more, it is in the realm of the highly sophisticated achievements of the human mind that excessive objectivity does the least harm. It is therefore most encouraging to have a volume like this, which makes a decidedly personal contribution to present-day thought, completely free from verbal complexity.

F. I. G. RAWLINS

\section{DRILL SCHOOL}

\section{Solving Problems in Dynamics I}

By R. R. S. Cox. Pp. 109. (Oliver and Boyd: Edinburgh and London, August 1968.) $15 s$.

\section{Solving Problems in Complex Numbers}

By D. Martin. Pp. 90. (Oliver and Boyd: Edinburgh and London, August 1968.) $15 s$.

Solving Problems in Vector Algebra

By E. M. Patterson. Pp. $v+144$. (Oliver and Boyd: Edinburgh and London, August 1968.) $17 s 6 d$.

Solving Problems in Differential Calculus

By L. M. Brown. Vol. 1: Pp. v +80 . 15ร. Vol. 2: Pp. 110. $12 s 6 d$. (Oliver and Boyd: Edinburgh and London, August 1968.)

THEse five small volumes form part of a new series of books, in which the authors have brought together a large number of worked examples together with sets of exercises and answers. They are not textbooks, although there is a summary of the relevant theory; rather they are meant to supplement textbooks and lecture courses, in the sense that the student can read through, in his own time, the detailed working out of the solutions.

The contents of the books in this series are taken at the level of about the final year at school and the first year (and perhaps part of the second) at university. They may be useful to students who have to teach themselves mathematics, and they may also be useful to lecturers at university who have classes too big for the provision of adequate tutorial classes.

Apart from chapter one of the first volume on the calculus, the books are written entirely in the classical spirit; and it might be asked whether undergraduates these days should spend so much time on all the drill and manipulation involved. Would it not have been better to have included some worked examples and exereises related to the so-called "new mathematics", where conceptis and their interrelations receive more emphasis than in most of the classical mathematics? It is already late for mathematicians to make a marriage between the "new" and the "old" mathematics. The present series would have provided an opportunity for the mingling of the spirits of the two branches. To this extent the series is disappointing. But for those students of technology and applied mathematics who are to be concorned only with the "old", the books provide a valuable basis for developing skill in manipulation and the working out of formulae.

L. S. GODDARD

\section{MESSIER OBJECTS}

\section{Messier's Nebulae and Star Clusters}

By Kenneth Glyn Jones. Pp. $480+12$ plates. (Faber and Faber: London, December 1968.) $150 s$.

MANY of the best known objects in optical astronomy, star clusters, galaxies, gaseous nebulac and planetary nebulae, were listed by Charles Messier towards the end of the eighteenth century. Some of the objects were already well known, while others were discovered by Messier himself. As a searcher for comets, he originally listed the objects to avoid confusion with possible comets but, ever since the publication of his catalogue, the objects have been universally known by the letter $\mathrm{M}$ followed by a number, such as M31-the Great Nebula in Andromeda.

This book is entirely concerned with Messier's cata. logue. I have found it a very interesting but also a rather unusual book. It is not, as might bo thought from its title, a collection of glossy photographs of the Messier objects although the book does contain a small photograph of each of them. The book starts with a general deseription of the different types of object which are included in Messier's catalogue, together with some background information about the universe and some remarks on present theoretical ideas on such matters as stellar evolution and the ages of star clusters. This introduction is followed by some advice about the equipment which amateur astronomers should use to obtain the best observations of the Messier objects and a discussion of what times of year and climatic conditions are likely to make observations difficult.

By far the largest part of the book is the chapter containing an account of each object in turn, including a history of early observations, a detailed description and a finding chart, and this diseussion fills about half of the book. It is followed by a historical and biographical section in which briof biographies are given of many of the astronomers mentioned in the previous section and there is a more extended account of the life of Messier. The book ends with various maps and listings of the objects and photographs of all of them.

This is a somewhat unusual and expensive book, solidly and well produced. It appears that the author's intention is that it should be read by amateur astronomers who are not yet familiar with the Messier objects. I cannot help feeling that many of them would prefer a very much cheaper book, probably a papcrback, containing finding charts and very brief descriptions of the objects, although there will be some who will prefer this very interesting reference book. In the section which I am most competent to criticize, I found a few major mistakes. For example, the relative luminosities of the Sun and RR-Lyrae stars are wrongly described on page 30, the central stars of planetary nebulae (page 46) are not believed to be massive, and the luminosities of stars are proportional to a relatively high power of mass (page 69).

R. J. TAYLER

\section{VIBRATION TECHNOLOGY}

\section{Simple and Complex Vibratory Systems}

By Eugen Skudrzyk. Pp. xiii +514. (Pennsylva nia State University Press: University Park, Pennsylvania, and London, November 1968.) 2298.

AT first sight, one has the impression that this is just another book on vibrations with the same old chapter hoadings as many others; it is only when one delves deeper into the text that it becomes apparent that here is something rather unusual.

The first six chapters are concerned with basic theory of the conventional systems having simple and multidegrees of frecdom and vibration of strings, bars and beams, but the treatment is unusual in that emphasis is placed on the similarity between electrical circuit and mechanical system responses and represents the physicist's approach to mechanical engineering problems. This is immediately clear from an examination of the diagrams which are representative of a book on electric circuit theory rather than mechanical systems. From the beginning the author converts the mechanical system into an electrical circuit analogy; mechanical symbols representing mass, spring and damping being replaced by an equivalent a.c. circuit containing eapacitance, inductance and resistance. 